Running Head: AGEISM AND DEATH

Ageism and Death: Effects of Mortality Salience and Perceived Similarity to Elders on Reactions to Elderly People

\author{
Andy Martens J Jeff Greenberg \\ University of Arizona \\ Jeff Schimel \\ University of Alberta \\ Mark J. Landau \\ University of Arizona
}

Reference:

Martens, A., Greenberg, J., Schimel, J., \& Landau, M.J. (2004). Ageism and death: Effects of mortality salience and similarity to elders on distancing from and derogation of elderly people. Personality and Social Psychology Bulletin, 30, 1524-1536.

Authors' Note: We thank Dorothy Kowalski and Lindsay Fry for all their help with this project. This research was supported by a grant from the National Science Foundation (Grant \#: SBR9729946). Please address correspondence to Andy Martens, University of Arizona, Department of Psychology, P.O. Box 210068, Tucson, AZ 85721-0068; e-mail: andym@u.arizona.edu.

\footnotetext{
Abstract

The present research investigated the hypotheses that elderly people can be reminders of our mortality and that concerns about our own mortality can therefore instigate ageism. In Study 1, college-age participants who saw photos of two elderly people subsequently showed more death accessibility than participants who saw photos of only younger people. In Study 2, making mortality salient for participants increased distancing from the average elderly person and decreased perceptions that the average elderly person possesses favorable attitudes. Mortality salience did not affect ratings of teenagers. In Study 3, these mortality salience effects were moderated by prior reported similarity to elderly people. Distancing from and derogation of elderly people after mortality salience occurred only in participants who, weeks before the study, rated their personalities as relatively similar to the average elderly person's. Discussion addresses distinguishing ageism from other forms of prejudice, as well as possibilities for reducing ageism.
} 
Ageism and Death: Effects of Mortality Salience and Perceived Similarity to Elders on Reactions to Elderly People

Elderly people are often and in various ways targets of prejudice. They are victims of discrimination in hiring and through forced retirement (e.g., Esposito, 1987), they are negatively portrayed in the media (e.g., Palmore, 1999), and are targets of stereotypes about competence and mental acuity (e.g., Cuddy \& Fiske, 2002; Kite \& Johnson, 1988). Furthermore, these practices are projected to be a problem of rapidly increasing magnitude, as the elderly population is expected to double over the next 30 years (Nelson, 2002). Understanding the intricacies and underpinnings of this understudied phenomenon - ageism - is therefore of increasing importance (Nelson, 2002).

The characteristics of ageism certainly have much in common with those of prejudice and discrimination aimed at other groups of people, and the elderly can be construed as an "outgroup" like other stigmatized groups. There is, however, an important distinction - the elderly are an outgroup that we are all on course to join someday. In this sense the perpetrators of ageism are connected to elderly people in a particularly intimate way that is not inherent in relationships to other outgroups. Why then does prejudice against elderly people exist? In this paper we will apply terror management theory (TMT; Greenberg, Pyszczynski, \& Solomon, 1986) to propose that ageism in some of its forms has to do precisely with this connection to elderly people, because it is potentially a potent and threatening reminder of our own aging process and of our ultimate fate - death.

Terror Management Theory

TMT developed out of the thinking of Ernest Becker $(1971 ; 1973 ; 1975)$, who theorized that a motivation to deny death can serve as a unifying concept for many models of human social thought and behavior. The reason for death's profound influence, Becker suggests, is that in humans we find an instinct for self-preservation combined with a capacity for selfconsciousness. Humans are aware of their own vulnerability and mortality while being driven to avoid death. Consequently, Becker posits that humans have an ever-present potential to feel terrified that can never be completely quelled.

TMT proposes that this difficult human predicament generates a fundamental motivation to manage the potential to feel terror. We do so by giving the world and ourselves meaning and value that transcends death and vulnerability. Specifically, by investing in a cultural worldview and securing self-esteem, we can convince ourselves that we are in some way not vulnerable to absolute annihilation because we have important and meaningful symbolic identities that are not subject to natural physical decay. Thus we maintain psychological composure. Ample research relevant to these issues shows that people who feel they are valuable, who have self-esteem, and who see the world as meaningful, are less anxious, less depressed, and generally more satisfied (e.g., Barnett \& Gotlib, 1988; Oatley \& Bolton, 1985; Taylor \& Brown, 1994).

Furthermore, a large body of research guided by TMT supports the idea that concerns about death motivate immersion in and loyalty to the larger culture as well as a need for selfesteem. The most common finding has been that priming people with the idea of their own death, referred to as mortality salience (MS), leads to exaggerated support for others who uphold the cultural worldview, and exaggerated derogation of those with differing worldviews (e.g., McGregor et al., 1998; Greenberg et al., 1990). In a similar vein, MS has been shown to increase bias in favor of people's ingroup as compared to an outgroup (Castano, Yzerbyt, \& Paladino, 2002; Harmon-Jones, Greenberg, \& Solomon, 1996). MS has also amplified self-esteem striving in the form of adjusting social identifications (Dechesne, Greenberg, Arndt, \& Schimel, 2000), 
bold driving in people for whom driving is important (Ben-Ari, Florian, \& Mikulincer, 1999), and greater reported investment in the body for people who's bodies are a source of self-esteem (Goldenberg, McCoy, Pyszczynski, Greenberg \& Solomon, 2000). In sum, brief reminders of mortality have consistently led to efforts to bolster the psychological structures, cultural meaning and self-esteem, that are theorized to protect humans from existential mortality concerns.

\section{Elderly People and TMT}

Given a human drive to be concerned about and defensive in response to the idea of one's own mortality, we believe that people may under some circumstances find elderly people threatening because they are reminders of one's own death. More specifically, we posit that this is the case because they are uniquely vivid and thus unsettling reminders of the human aging process that leads to death. When people see themselves reflected in an elderly person, they on some level become aware that they are the same flesh and blood, made of the same material, and subject to the same natural laws and fate. As Susanne Langer (1982) argues, an elderly person can be a potent psychological threat because in them we see that even if we eat right, make money, become popular, and even if we avoid drowning and airplane crashes and disease, we are still aging and thus will eventually die. Though we can easily convince ourselves that we will sidestep premature death by means of our intellect or resilience or luck, aging and time are uncompromising - they always lead to death. Therefore, when we see ourselves in an elderly person, we may see that our own life too is ephemeral, uncontrollably slipping away. Consistent with this, for example, are the "profound existential responses" including death anxiety and a heightened sense of vulnerability that younger therapists report as they become connected to elderly clients through the transference process (Bennett, 2002, p. 2573).

The crux of our argument, then, is that because elderly people fuel our existential fears by their association with death and our intimate connection to them, we tend to psychologically distance from them. By loosening our connection to elderly people, by avoiding seeing ourselves in them, elderly people's connection to death may not seem to imply our own. In Simone de Beauvoir's (1972) words, we may come to see elders not "as real people" but "as different, as another being" (pp. 2-3). Furthermore, through engaging in this defense, we may also come to view elderly people in a lesser and unfavorable light.

Theorizing and research suggesting that we distance from and disparage those who have qualities we fear in ourselves is consistent with this possibility (Jung, 1959; Schimel, Pyszczynski, Greenberg, O'mahen, \& Arndt, 2000; Taylor \& Mettee, 1971). Applying this theory to ageism, Rodin and Langer (1980) have reported data that though elderly people are generally more positive than non-elderly people towards an elderly target, they can be less positive than non-elderly people if the older target shows signs of forgetfulness. Further, several studies have found that greater self-reported death anxiety predicted more negative attitudes towards elderly people (Depaola, Griffin, \& Young, 2003; Hunter, Linn, \& Pratt, 1979; Schwiebert, 1978).

The present studies build on these ideas and our terror management analysis of ageism by assessing several hypotheses. The first study tests our assumption that people associate elderly people with death. The second study examines the hypothesis that concerns about one's own death can instigate distancing from and derogation of elders. The third study tests the hypothesis that ageist reactions stemming from death concerns are especially prevalent in people who perceive similarities between themselves and elderly people. It is in these cases that the association between death and elderly people should be the most threatening reminder to people that their own life too is inescapably transient. 


\section{Study 1}

To assess whether people tend to associate elderly people with death, we had college age participants view either pictures of young adults, or pictures of both young and elderly adults. Then we measured death thought accessibility using a word-stem completion task similar to that developed by Greenberg, Pyszczynski, Solomon, Simon, and Breus (1994). Participants completed 26 word fragments, eight of which could be completed in a death-relevant way. If pictures of elderly individuals remind participants of death, those exposed to these pictures (vs. only non-elderly pictures) should complete more words in a death-relevant way.

\section{Participants}

\section{Method}

Ninety-seven undergraduates (63 females, 32 males, and 2 unknown/unreported) at the University of Arizona participated for partial course credit. Though we failed to record particpants' ages, the vast majority of students in the pool of participants were between 18 and 21 years of age, with a mean of 19.06 years of age. Three were excluded because they were not proficient in English and thus could not easily complete the death accessibility measure. One participant was excluded because of suspicion about the word fragment completion form. This left a total sample of 93 participants.

Procedure

The experimental sessions took place in a classroom in groups of between 3 and 15 people. Participants received a packet and were told that the purpose of the study was to look at how people respond to imagery in written form as compared to photographic images. ${ }^{1}$ The first part of the packet was a written passage from a novel in which a protagonist passes a person on a bridge on a rainy night and later hears ambiguous sounds. Following this passage, participants received several questions that are irrelevant for the description of the present study. The next four pages each contained a picture of a person with questions below. The questions below each picture were "How attractive would you guess this person is to the opposite sex?", "How tall would you guess this person is?", "How powerful would you guess this person is?", "How anxious/calm would you guess this person is?", and "How cowardly/courageous would you guess this person is?" All questions were answered on a 9-point scale except the one regarding height.

The pictures served as the independent variable. Approximately half the participants viewed four pictures of young adults, and the other half viewed two pictures of young adults followed by two pictures of elderly adults. We did not show participants pictures of all elderly people in the elderly condition so as not to arouse possible suspicion that we were interested in the effects of viewing elderly people. The young adults consisted of two sets of a woman and a man. In the young pictures only condition, the order of these two sets (first woman/man set vs. second woman/man set) was counterbalanced. In the elderly condition, the presence of the young adult sets was counterbalanced and followed by pictures of an elderly woman and elderly man. All the pictures showed people only from the shoulders up. Further, all the pictures depicted people who looked relatively healthy, though the elderly people of course clearly showed signs of aging that the younger people did not, such as deep wrinkles, graying hair, thinning hair, and glasses. Further, in a pilot test with 8 participants, we assessed perceptions of the elderly targets' age. Ratings of the elderly man ranged from 63 to 82, with a mean of 71 years of age; ratings of the elderly woman ranged from 68 to 90 with a mean of 78 years of age. Thus, it is clear that they were perceived as elderly. 
Once all participants viewed and rated the pictures, the experimenter asked the participants if they would quickly fill out one last form, and passed out a death accessibility measure (adapted from Greenberg, Pyszczynski, Solomon, Simon, and Breus, 1994). In order to prevent participants from consciously connecting this accessibility measure to the pictures, the experimenter introduced it as a new measure being pre-tested for a future study. The death accessibility form consisted of 26 word fragments that participants were instructed to complete with the word that first came to mind. Eight of these words fragments had the potential to be completed with death-related words. For instance participants viewed the fragment GRA _ _, which could be completed in a death-related way with the word GRAVE, or in death-neutral ways, such as with the words GRAPE or GRAIN. In addition to grave, the other possible deathrelated items were dead, buried, killed, skull, coffin, corpse, and stiff. When all participants completed the death accessibility measure, they were carefully probed for suspicion and debriefed.

\section{Results and Discussion}

An ANOVA was performed to determine if participants exposed to the pictures of elderly individuals exhibited greater death accessibility than those exposed only to pictures of young adults $^{2}$. Supporting our prediction, those who viewed the elderly pictures completed more word fragments with death-related words $(M=2.75, S D=1.28, N=46)$ than those viewing only pictures of younger adults $(M=2.23, S D=1.27, N=47), F(1,91)=3.81, p=.05$, Cohen's $d=$ 41 .

\section{Study 2}

Given this connection between the elderly and death, we posited that concern about mortality would generate distancing from and derogation of elderly people as a way of denying their own vulnerability to aging and death. To this end we manipulated mortality salience (MS) and subsequently assessed perceived similarity to the average elderly and teenage person with a measure closely modeled after a social projection measure used by Simon et al. (1997) and Arndt, Greenberg, Solomon, Pyszczynski, and Schimel (1999), and originally adapted from Krueger and Clement (1994). Briefly, this and related measures have fruitfully assessed social projection by assessing participants' agreement with various statements in addition to their opinions about the percentage of others who would agree with the statements. By correlating these two sets of ratings one can then acquire an index of consensus, or how much people believe they and the rated others are alike.

In our version, participants were asked to rate their agreement with a number of statements and then to rate the level of agreement they thought the average elderly person and the average teenager would indicate. We reasoned that the more highly correlated self-ratings were with elderly or teenager ratings, the greater the feeling of similarity between participants and the target age group. We also felt that assessing participants' connection to the target groups in this subtle way would allow us to better avoid problems such as demand characteristics that more explicit measures may be likely to elicit. After completing self and target ratings, participants rated the desirability of agreeing with the various statements. We included this measure to help assess the extent to which participants attributed favorable attitudes toward the elderly and teenagers. We reasoned that the more the elderly or teenager ratings correlated with the ratings of the desirability of the attitudes, the more favorably participants viewed the target group. We predicted that after MS, the college-aged participants would view the average elderly person's attitudes as especially different from their own and as especially unfavorable.

\section{Method}




\section{Participants}

One-hundred and five introductory psychology students (69 females and 36 males) participated for course credit. The mean age of participants was 18.65 years old, though we were not able to acquire the ages of 28 of the participants because they did not participate in a prescreening session. However, the mean age of the pool the participants were drawn from, 18.97 years old, is consistent with participants' mean age in the current study. Five participants were excluded because they had recently participated in a MS study; another 3 were excluded due to suspicion, and 1 did not follow directions when completing the dependent measures. This left 96 participants for analysis.

\section{Procedure}

Participants entered the laboratory in groups of between 2 and 5 . They were told that the purpose of the session was to look at how personality characteristics of people of different ages are the same and different. They therefore would first fill out a packet of personality measures, ostensibly also administered to people of other age groups for purposes of comparison. In addition, the experimenter explained that the research was concerned with how people of different generations view each other, and in the service of answering this question participants would later rate other randomly chosen age groups on various characteristics. After this introduction, participants entered individual cubicles and read and signed a consent form.

Next, the experimenter distributed the packet of "personality measures." The real purpose of the packet, however, was not to assess personality, but to manipulate MS. Three of the four questionnaires were identical for all participants, but the third form either primed participants with death or with a negative control topic, dental pain. The MS form asked participants in an open-ended format to "Please briefly describe the emotions that the thought of your own death arouses in you" and to "Jot down, as specifically as you can, what you think will happen to you as you physically die and once you are physically dead." The control questionnaire was essentially the same except asked participants to describe experiencing dental pain instead of death. The first two questionnaires in the packet were bogus fillers and the final page of the packet was an affect measure, the PANAS-X (Watson \& Clark, 1991), which served as a distraction and delay between MS and the dependent measure (cf., Greenberg et al., 1994).

When participants finished the first "personality" packet, they notified the experimenter that they were ready for the next part of the study. The experimenter then entered each cubicle to administer the first segment of the dependent measure. It was a form that contained 16 statements, such as "I like poetry," "I would like to be a singer," "I am a very sociable person," and "I like to be with a crowd who play jokes on one another." Participants were instructed to first rate themselves as either agreeing or disagreeing with each statement on a scale from 0 to 100 percent. They completed these ratings in a column headed "self," next to which were 5 other columns with the headings "elderly," "middle-aged," "young adult," "teenager," and "pre-teen."

Once the self-rating task was finished, the experimenter re-entered the cubicle with a basket from which participants picked a piece of paper indicating the generation they would first rate. This was in keeping with the cover story (that participants were rating randomly selected generations) to ensure that participants did not know we were interested specifically in their reactions to elderly people. In reality, the pieces of paper in the basket were all labeled with the same age group, either elderly or teenagers. Once the first age group was selected from the basket, participants were instructed to rate that age group using the appropriate column with the percent they thought the average person of that generation would agree with each of the 16 statements. The experimenter also opened a folder in which there were a number of copied 
photographs, and handed participants a picture of a group of females from the generation to be rated. The pictures were from a nursing home and a summer camp, for the elderly and teenagers, respectively, and were presented to help participants with their ratings. The experimenter described these groups as people who previously took part in the study, though made it clear that men also participated even though there were no available pictures of them.

After the participants rated the first age group, either elderly people or teenagers, the experimenter entered the cubicle again with the basket and participants picked and rated the second age group. The order in which participants rated the target age group was counterbalanced, such that approximately half the participants rated the average elderly person first and half rated the average teenager first. After these age group ratings, the experimenter brought participants a separate form to procure social desirability ratings for each of the 16 statements. Participants rated how desirable they felt it was to agree with each statement on a scale from 1 to 9 , where 1 is totally undesirable and 9 is totally desirable.

In sum, after participants rated their own agreement with the statements they, in counterbalanced order, rated elderly people and teenagers on the same statements while viewing a picture of people in the age group they were rating. They then rated the desirability of agreeing with each statement.

\section{Distancing Analysis}

\section{Results and Discussion}

We hypothesized that reminders of mortality would reduce participants' perceptions of similarity to the elderly, the group close to death. To test this we first computed for each participant two sets of correlations, one between participants' self and elderly ratings, and one between self and teen ratings. High positive numbers reflected perceived similarity between participants and the target generation, whereas low, negative numbers reflected perceived dissimilarity and distancing from the target generation. Thus, each participant had a score between him/herself and the elderly and between him/herself and teenagers. These correlationscores were entered into a 2 (MS: mortality vs. dental pain) X 2 (gender: male vs. female) X 2 (target: elderly vs. teen) X 2 (order: elderly first vs. teens first) ANOVA, with the target treated as a repeated measures variable.

\section{Interaction Hypothesis: MS and Distancing from Elderly People}

The expected MS by target interaction was significant, $F(1,88)=4.21, p<.05$. Table 1 presents the pattern of distancing correlation-scores. Pair-wise comparisons revealed that both within the MS condition and within the control condition, the average elderly person was viewed as more different than the average teenager, $t(47)=7.55, p<.01, d=1.63$, and $t(47)=3.87, p<$ $.01, d=.93$, respectively. However, distance from the average elderly person was clearly greater in the MS condition than in the control condition, $t(94)=2.52, \mathrm{p}<.05, d=.54$. Distance from the average teenager was not affected by MS, $t(94)=.44, p>.6$.

Other Effects

The four-way ANOVA also revealed a main effect for target, $F(1,88)=69.17, p<.01$, indicating that teenagers $(M=.42, S D=.31)$ were generally viewed as more similar than elderly people $(M=03, S D=.31), d=1.25$. This is of course not surprising because the participants were closer in age to the teenagers. The ANOVA also revealed a main effect for gender, $F(1,88)$ $=17.71, p<.01$. Females $(M=.31, S D=.20)$ saw themselves as more similar to the targets in general than did males $(M=.13, \mathrm{SD}=.20), d=.85$. This gender effect may have emerged or been facilitated because the pictures of elderly and teenage individuals that participants viewed were of females only ${ }^{3}$. 


\section{Favorability Analyses}

On the final questionnaire, participants rated the desirability of each statement on which they rated themselves and the target groups. Inclusion of these social desirability ratings allowed us to examine the extent to which participants viewed the elderly people and teenagers in a positive or negative light. Specifically, two sets of correlations were computed for each participant, one between social desirability ratings and elderly ratings, and one between social desirability ratings and teenager ratings. High positive correlations indicated that participants positively viewed the attitudes they perceived the target group as likely to possess. Thus, higher correlations reflected perceiving the target group more favorably. These correlation-scores were entered into a four-way ANOVA (MS X gender X target group X order).

Interaction Hypothesis: MS and Derogation of Elderly People

The expected MS X target group interaction was significant, $F(1,88)=3.95, p=.05$. The pattern of favorability correlation-scores is presented in Table 2. Mirroring the distancing effects, pairwise comparisons showed that both within the MS and control condition, elderly people were viewed less positively than teenagers, $t(47)=6.70, p<.01, d=1.54$, and $t(47)=4.10, p<.01, d$ $=.84$, respectively. In addition, ratings of elderly people were less favorable in the MS condition than in the control condition, $t(94)=1.96, p=.05, d=.52$. Favorability towards teenagers was not affected by MS, $t(94)=.46, p>.6 .^{4}$

Other Effects

As was the case in the distancing analysis, there were also two main effects, one for target group, $F(1,88)=59.36, p<.01$, and one for gender, $F(1,88)=8.21, p<.01$. The teenagers were rated more positively $(M=.39, S D=.30)$ than elderly people $(M=.04, S D=$ $.31), d=1.15$, and females viewed targets more favorably $(M=.28, S D=.21)$ than males $(M=$ $.15, S D=.20), d=.63$.

Affect Analysis

The affect subscales of the PANAS-X (Watson \& Clark, 1991) were entered into a 2 (MS) X 2 (gender) multivariate analysis of variance (MANOVA) to assess whether these variables, alone or in combination, predicted participants' mood. No multivariate effects approached significance, all $p \mathrm{~s}>.3^{5}$.

The results of Study 2 provided clear support for our hypothesis. After being reminded of their own death, participants rated elderly people's attributes as especially different from their own, whereas MS did not affect distancing from teenagers. Furthermore, after being reminded of their own death, participants viewed elderly people less positively than in the control condition, an effect that also did not occur for ratings of teenagers.

Study 3

In Study 3 we sought to further test our perspective on ageism that it is a form of prejudice different in some respects than that directed at people merely because they are part of an outgroup. We argue that in order to understand ageism, one should take into account the unique connection between the perpetrators and targets - that the non-elderly are becoming elderly. In doing so, we posited that the effects of Study 2 were not necessarily a simple case of MS increased derogation of different others whose worldview is a threat. Instead we posited that the Study 2 effects occurred because the participants could see themselves in the elderly targets and, especially after MS, were threatened by this prospect. They are a threat to the efficacy with which we manage existential concerns to the extent that, whether consciously or unconsciously, we can see ourselves in them. Thus, following MS, those who perceive similarities between themselves and elderly people should distance from and derogate them the most. 
We examined this proposal by recruiting college-age participants for a study very similar to Study 2. These participants, however, rated the perceived similarity of their personality to the average elderly person's in a mass testing session weeks before the experiment. With these ratings, we were therefore able to test the hypothesis that those who saw aspects of themselves in elderly people would be most likely to distance and/or derogate them after MS.

Study 3 also allowed us to address an alternative account for the MS effects in Study 2. Some have suggested that MS may arouse uncertainty concerns (McGregor et al., 2001; van den Bos \& Miedema, 2000). If this was the case, maybe uncertainty concerns not tied to death led people to distance from elderly people because they are unwanted reminders of an uncertain future. To control for this possibility, in Study 3 we substituted an uncertainty salience questionnaire (adapted from van den Bos, 2001) for the pain salience control questionnaire used in Study 2.

\section{Participants}

\section{Method}

Sixty-eight female introductory psychology students participated for course credit. In Study 2, as indicated by the experimenter, approximately half of the male participants expressed concern or confusion about how they should rate the age groups when they received the photos of only female target groups. Though it did not appear to lead to any sex effects in Study 2, and the experimenter informed participants that both males and females should be considered when rating the average elderly or teenage person, we nevertheless, unable to acquire different photographs in time, recruited only females for Study 3. Two participants were excluded because they did not follow directions when completing the dependent measures, and 1 was excluded because she left the laboratory for approximately 10 minutes in the middle of the experiment. This left 65 participants for analysis.

\section{Procedure}

The procedure for Study 3 differed only slightly from that of Study 2. On a mass prescreening that took place at the beginning of the semester, participants answered a question about similarity to elderly people. The question was "How similar is your personality to the average elderly person's?" and was answered on 9-point Likert scale ( $1=$ "not at all similar," $5=$ "moderately similar," and 9= "extremely similar").

The nature of the control condition in Study 3 was also different than in Study 2. Instead of answering two open-ended questions about dental pain, control participants answered two open-ended questions about uncertainty. These questions, almost identical to the death questions, were "Please briefly describe the emotions that the thought of your being uncertain arouses in you" and "Jot down, as specifically as you can, what you think will happen to you as you experience uncertainty and once you have experienced uncertainty." A bogus questionnaire preceded the MS or uncertainty questionnaires, and the PANAS-X and an open-ended questionnaire about self-esteem sources ${ }^{6}$ followed the MS manipulation.

\section{Distancing Analysis}

\section{Results and Discussion}

Just as in Study 2, we measured psychological distancing from elderly people and teenagers by computing 2 correlation-scores for each participant between (1) his/her self ratings and his/her ratings of the average elderly person, and (2) between his/her self-ratings and his/her ratings of the average teenage person. We first entered these scores into a 2 (MS: mortality vs. uncertainty) X 2 (target: elderly vs. teen) $\mathrm{ANOVA}^{7}$, with the target treated as a repeated measures variable. As in Study 2, a main effect for target emerged, $F(1,63)=15.18, p<.01$, 
such that participants were more distanced from the average elderly person $(M=.19, S D=.33, N$ $=65)$ than the average teenager $(M=.41, S D=.28, N=65), d=.71$. Also, the MS by target interaction was marginally significant, $F(1,63)=3.72, p=.058$. Replicating Study 2, pairwise comparisons indicated that participants distanced from elderly people more after MS $(M=.11$, $S D=.36, N=30)$ than in the control condition $(M=.27, S D=.29, N=35), t(63)=2.04, p<$ $.05, d=.51$, but did not distance more from teenagers after MS $(M=.44, S D=.26, N=30)$ as compared to the control $(M=.38, \mathrm{SD}=.29, N=35), t<1$.

We next sought to test our hypothesis that those who prior to the experiment reported feeling more similar to elderly people would be those most prone to distance from them after MS. To examine this, we regressed the elderly distancing scores onto MS, prior similarity to the elderly, and the MS by prior similarity interaction term. In addition to a significant main effect for MS, $B=.17, S E=.078, t=2.18, p<.05$, the MS by prior similarity interaction was marginally significant, $B=.097, S E=.05, t=1.94, p=.057$. Following Aiken and West (1991), we examined this interaction by testing the effect of MS for those higher (1 SD above the mean) and lower ( $1 \mathrm{SD}$ below the mean) in prior similarity $(M=4.25, S D=1.57)$. Participants reporting higher prior similarity to elderly people, distanced after MS as compared to the uncertainty control condition, $B=.322, S E=.11, t=2.92, p<.01$. Those lower in prior similarity did not distance further from the elderly after MS as compared to the control condition, $B=.018, S E=.111, t=.16, p>.8$. However, as the representation of this analysis in Figure 1 shows, these low similarity participants were already quite distanced in the uncertainty control condition. Observed from another perspective, within the uncertainty condition, the more prior similarity to elderly people, the more similarity with elderly people participants showed on the dependent measure, $B=.385, S E=.035, t=2.32, p<.05$. However, within the MS conditions, this relationship was eliminated such that prior similarity no longer predicted similarity on the dependent measure, $B=-.077, S E=.036, t=-.453, p=.65$. Lastly, As expected, MS and prior similarity did not interact to affect distancing from teenagers, $B=.018, S E=.045, t=.39, p=.7$. Favorability Analysis

As in Study 2, we quantified how desirable participants viewed the attributes of elderly people and teenagers by computing correlations between the attribute ratings of each of these target groups and the desirability rating of the attributes. These scores were first entered into a 2 (MS: mortality vs. uncertainty) X 2 (target: elderly vs. teen) repeated measures ANAOVA. As in Study 2, a main effect for target emerged, $F(1,63)=34.64, p<.01$, such that target-desirability correlations were less favorable for the average elderly person $(M=.10, S D=.33)$ than the average teenager $(M=.43, S D=.28), d=1.11$. In addition, the MS by target interaction approached significance, $F(1,63)=2.77, p=.10$. The pattern of means, though non-significant, suggested that, as in Study 2, MS led participants to be more unfavorable towards elderly people $(M=.03, S D=.32)$ than in the control condition $(M=.15, S D=.33), t(63)=1.47, p=.15, d=$ .38. The pattern of means for teenagers showed an opposite trend toward reduced distancing after MS $(M=.47, S D=.24)$ compared to after uncertainty $(M=.40, S D=.31), t(63)=.88$.

We next sought to qualify this analysis and test our hypothesis that those who prior to the experiment reported feeling more similar to elderly people, would be those most prone to derogate them after MS. Thus, we regressed the elderly-favorability scores onto MS, prior similarity to the elderly, and the MS by prior similarity interaction term. Only the MS by prior similarity interaction reached significance, $B=.106, S E=.05, t=2.10, p<.05$. As with the distancing analysis, we examined this interaction by testing the effect of MS for those higher (1 $\mathrm{SD}$ above the mean) and lower ( $1 \mathrm{SD}$ below the mean) in prior similarity $(M=4.25, S D=1.57)$. 
Participants reporting higher prior similarity to elderly people were less favorable towards elderly people after MS as compared to the uncertainty control condition, $B=.290, S E=.11, t=$ $2.60, p=.01$. Those lower in prior similarity did not become less favorable towards elderly people after MS as compared to the control condition, $B=-.043, S E=.11, t=-.38, p>.7$. This analysis is represented in Figure 2. Viewed from a different perspective, within the uncertainty condition, a trend emerged for such that the more prior reported similarity to elderly people, the more favorability participants showed toward elderly people on the dependent measure, $B=.290$, $S E=.035, t=1.71, p=.09$. However, in the MS conditions, this pattern of association between prior similarity and favorability was in the opposite direction, though not significant, $B=-.22$, $S E=.036, t=-1.26, p=.21$. Lastly, MS and prior similarity did not interact to affect distancing from teenagers, $B=.002, S E=.045, t=.051, p>.9$.

Affect Analysis

We conducted a multivariate regression to assess whether MS, prior similarity to elderly people, or the interaction of these two independent variables, predicted the affect subscales of the PANAS-X (Watson \& Clark, 1991). As in Study 2, no omnibus effects were significant, all $p s>$ $.3^{8}$. In addition, examining the direction of the condition means of the subscales showed that potentially relevant ones such as fear and negative mood were higher in the uncertainty condition then in the MS condition. This is consistent with a large body of prior evidence indicating that MS effects are not a consequence of negative affect (e.g., Arndt, Greenberg, Solomon, Pyszczynski, \& Simon, 1997; Rosenblatt et al., 1989).

The results of Study 3 provided clear support for our hypothesis. After being reminded of their own death (vs. uncertainty), participants who previously reported feeling relatively similar to elderly people, showed pronounced distancing from and derogation of elderly people.

Participants who did not report these feelings of prior similarity did not respond more negatively to elderly people after MS. Also, MS and prior similarity did not affect responding to teenagers.

\section{General Discussion}

Taken together, the results of the three studies supported our hypotheses. First, Study 1 demonstrated that people appear to associate elderly adults with death. Participants who saw photos of two elderly people subsequently completed more word fragments with death-related words than did participants who saw only pictures of younger people. Second, Study 2 showed that MS, reminders of mortality in the form of an open-ended death questionnaire, induced participants to exaggerate the differences between their ratings of themselves and of the average elderly person, and also reduced the favorability of the elderly ratings. MS, however, did not affect distancing from or favorability towards teenagers. Third, Study 3 demonstrated that this MS-instigated distancing and derogation occurred primarily in those people who, weeks prior to the experiment, rated their personalities as similar to elderly people's. This effect also did not occur with ratings of teenagers.

These results suggest that concerns about death can lead to exaggeratedly ageist reactions because of people's connection to elderly people. In addition, these results are inconsistent with an alternative hypothesis for MS induced ageism that it occurs simply because the elderly generation is an outgroup. Indeed, MS has produced bias in favor of people's ingroups relative to outgroups who with their differences may threaten the validity of one's worldview (e.g., Harmon-Jones, Greenberg, \& Solomon, 1996; Castano, Yzerbyt, \& Paladino, 2002). If this were the case in Study 3, however, participants would show exaggeratedly ageist ratings after MS only when they previously reported feeling dissimilar to elderly people. Instead, the results were opposite. This strongly suggests that the unique relationship between the elderly outgroup and 
non-elderly ingroup should be taken into account in attempting to understand how ageism is tied to fears of being mortal. What may be most threatening about elderly people is not that they are so very different, but that they are the same - and thus that their fate is the same fate bestowed upon the non-elderly.

In Studies 2 and 3, participants also appeared to be more distanced from and unfavorable towards elderly people than teenagers even without a MS induction. This could be due to a purely rational thought process. Participants, being college students, were much closer in age to teenagers than to elderly people and thus it is quite likely that their attitudes would in fact be closer to those of teenagers. However, this main effect could also be the result of terror management needs. Because, as shown in Study 1, elderly people may at least in some circumstances be associated with death, distancing from and derogation of elderly people may occur automatically in people to preemptively avoid the existential threat older adults are capable of posing. This would be consistent with two studies documenting psychological distancing from someone with a life-threatening disease, someone who, like an elderly person, can be a reminder of death if one acknowledges similarity (Pyszczynski, Greenberg, Solomon, Sideris \& Stubing, 1993, Study 2; Pyszczynski, Greenberg, Solomon, Cather, Gat, \& Sideris, 1995).

This explanation suggests that perhaps even in the control conditions in Studies 2 and 3, participants were under mortality salience simply because they all viewed a picture of elderly people. In this case, the differences observed between the open-ended mortality salience conditions and the control conditions may have been the result of exaggerating already heightened death-accessibility. This in turn suggests that mortality salience inductions might be additive. This seems consistent with prior work showing that varying the duration and thus degree of a construct's accessibility also varies the influence that the construct exerts on thinking and behavior (e.g., Dijksterhuis \& van Knippenberg, 1998). It is also possible that defensive distancing is only triggered when death thought accessibility reaches a threshold that simply was not reached in the control conditions.

Yet another possibility is that the single elderly group picture taken from a distance did not raise death accessibility the way the more vivid close-ups of elderly people the participants focused on in Study 1 did. In addition, perhaps the death-accessibility instigated in Study 1 by pictures of elderly people indicated only that participants associated elderly people with death. This death accessibility may not have by itself led to an association with one's own death. Greenberg et al. (1994) and Nelson, Moore, Olivetti, and Scott (1997) provided evidence suggesting that death-related stimuli lead to terror management defenses only to the extent that they encourage focus on one's own death. For example, Nelson et al. showed American participants fatal accident footage and found that only those participants who connected the footage to their own vulnerability exhibited increased bias in favor of an American auto manufacturer relative to a Japanese auto manufacturer.

\section{Limitations}

One limitation of the ageism findings is that we do not know what the distancing and favorability measures mean for people's behavior. Participants psychologically distanced from and indexed less favorable attitudes about elderly people after MS, but it is not as clear whether MS would also lead to physical distancing or blatant discrimination. Though the research is at this point is scant, most ageism researchers agree, however, that negative attitudes about elderly people have implications for behavior (e.g. Kite and Wagner, 2002; Perdue \& Gurtman, 1990; Montepare \& Zebrowitz, 2002; Pasupathi \& Lockenhoff, 2002). In addition, negative attitudes 
towards other targets of prejudice have been linked to behavior consistent with these attitudes (e.g., Dovidio et al., 1997; McConnell \& Leibold, 2001).

Another limitation was that only women participated in Study 3. Thus, we do not know whether men would exhibit the same pattern of distancing and derogation. It seems plausible, however, considering men did show the same ageism related responses after MS in Study 2. Furthermore, research on a similar phenomenon - distancing from others who poses traits one fears in one's self-has not shown gender differences (Schimel et al., 2000; Taylor \& Mettee, 1971). Nevertheless, these studies are certainly not exhaustive tests of these ideas, and should ideally serve as a springboard for future research and theory concerning ageism and mortality fears as they affect both women and men.

Implications for Ageism

Despite the present work's limitations, this research may be of increasing relevance and importance for several reasons. First, the elderly population is increasing due to advancements in medicine. Consequently, ageism is a problem that is affecting more and more people. Second, also from advancements in medicine, more and more people are dying during old age rather than "prematurely", suggesting that aging and elderly people will increasingly become a threat to people's ability to manage death-related fear. As aging becomes an increasingly likely way we will die, aging, along with reminders of aging such as elderly adults, should become only more threatening. Third, TMT's analysis suggests that the more prejudice is directed at elderly people, the more people will have to fear about them. That is, the more people derogate elderly individuals, the more elderly people will reflect not only a future that leads to death, but one in which we will not be protected by a feeling that we are culturally valued.

From these concerns, it may be increasingly important to address ageism directed at the elderly in a number of ways, such as with policy changes (Braithwaite, 2002), with the media (Palmore, 1999), with education, and with contact (Shanks, 1976). In addition, our theoretical perspective suggests that another approach to reducing ageism might be learning to better cope with the various concerns related to our own aging and mortality. Research, however, is equivocal with regard to the efficacy of such a tactic. For one, a meta-analysis suggested that death education, opposite to predictions, leads to greater death anxiety (Maglio \& Robinson, 1994). Another investigation, however, showed reduced death anxiety as a consequence of death education (Davis-Berman, 1998-1999). This study, though, did not find reduced ageism, whereas a class on aging taught by the same instructor reduced ageist attitudes as well as death anxiety. Thus, the consequences of death education for ageism are mixed and unclear. Certainly there are many approaches to teaching such classes, as well as many approaches to measuring death anxiety and ageism. Investigating these approaches and their implications more deeply seems an important avenue for future work.

Another approach to decreasing ageism may be to investigate the possibility that elderly people and aging can trigger self-esteem threats. One particularly upsetting part of growing old may be the limiting of possibilities. As one ages, the possibility for various life experiences narrows until in the end the range is very small. Some goals and aspirations that give life direction, energy, and value when people are young become impossibilities with old age. Thus, in elderly people we may not only see the facts of mortality, but the inevitable hopelessness of our worldview-based aspirations and bases of self-worth, particularly if those worldviews are centered around things that the elderly can no longer do so well (e.g., athletics, have children, etc.). Not only may elderly people be reminders of death, but reminders that our psychological defenses against death, i.e., our sense of meaning and value, are fleeting. 
From this perspective, a possibility for reducing the threat of the elderly and the ageism that may ensue might be broadening our values and what makes our lives meaningful. If people value in themselves qualities that are strengths of the elderly, such as wisdom, a sense of humor about the dark side of life, or achieving close and rich relationships (Lang \& Carstensen, 2002), perhaps people will have less to fear in elderly people. Or, if people cannot change their own sources of self-esteem, perhaps people and culture can still imbue elders with more value than appears to be currently the case. If this occurs we may not see as strongly in the elderly an existence that is lacking meaning; as a consequence, we may be less motivated to distance from and derogate elderly people.

Nevertheless, if TMT is correct and we want very much to live in the most secure and death-free way possible, then elderly people are always a potential threat to our equanimity. Elderly people have an uncanny way of exposing the existential dilemma we all can understand on some level, and yet want very much to be free of. They are a living symbol of time running out, of faculties fading, of potentially frightening biological facts. But of course they are also people who feel the devastating emotional effects of prejudice and are people who are contending, often in a much more direct way than others, with their own finitude. For these reasons we should be conscious of the possibility that, as the current research suggests, our own fears may motivate us to ignore and belittle and isolate the old. In addition, the Study 3 findings suggest that these tendencies may emerge particularly strongly in cases that both older and younger people most care about, for instance, with family members. It is in these situations, when we are closest to the older person-when it is easiest to see ourselves in that person-that it may be easiest to feel threatened and lash out or simply avoid the aging friend or parent. Perhaps the more we understand how our fears related to the aging process and death interact with our connections to elderly people, the more we will temper the tendency to differentiate ourselves from them, to view and treat them like "another" or lesser being. From this there might even emerge the possibility of learning from those who are closest to dealing with somethingthe end of life - that we all must face. 


\section{References}

Aiken, L.S., \& West, S.G. (1991). Multiple regression: Testing and interpreting interactions. London: Sage Publications.

Arndt, J., Greenberg, J., Solomon, S., Pyszczynski, T., \& Schimel, J. (1999). Creativity and terror management: Evidence that creative activity increases guilt and social projection following mortality salience. Journal of Personality and Social Psychology, $77,19-32$.

Arndt, J., Greenberg, J., Solomon, S., Pyszczynski, T., \& Simon, L. (1997). Suppression, accessibility of death-related thoughts, and cultural worldview defense: Exploring the psychodynamics of terror management. Journal of Personality and Social Psychology, 73, 5-18.

Barnett, P.A., \& Gotlib, I.H. (1988). Psychosocial functioning and depression:

Distinguishing among antecedents, concomitants, and consequences. Psychological Bulletin, 104, 97-126.

Becker, E. (1971). The birth and death of meaning. New York: Free Press.

Becker, E. (1973). The denial of death. New York: Free Press.

Becker, E. (1975). Escape from evil. New York: Free Press.

Ben-Ari, O. T., Florian, V., \& Mikulincer, M. (1999). The impact of mortality salience on reckless driving: A test of terror management mechanisms. Journal of Personality and Social Psychology, 71, 35-45.

Bennett, M.A. (2002). The therapist's transference: Younger therapists working with older adults. Dissertation abstracts International, 63 (5-B), 2573.

Braithwaite, V. (2002). Reducing ageism. In T.D. Nelson (Ed.), Ageism: Stereotyping and prejudice against older people (pp. 311-337). Cambridge, MA: MIT Press.

Castano, E., Yzerbyt, V., \& Paladino, M. (2002). I belong, therefore, I exist: Ingroup identification, ingroup entitativity, and ingroup bias. Personality and Social Psychology Bulletin, 28, 135-143.

Cuddy, A.J.C., \& Fiske, S.T. (2002). Doddering but dear: Content, and functioning in stereotyping of older persons. In T.D. Nelson (Ed.), Ageism: Stereotyping and prejudice against older people (pp. 3-26). Cambridge, MA: MIT Press.

Davis-Berman, J. (1998-1999). Attitudes toward aging and death anxiety: Aging and death class. Omega: Journal of Death \& Dying, 38, 59-64.

de Beauvoir, S. (1972). The coming of age. New York: G.P. Putnam's Sons.

Dechesne, M., Greenberg, J., Arndt, J., \& Schimel, J. (2000). Terror management and the visissitudes of sports fan affiliation: The effects of mortality salience on optimism and fan identification. European Journal of Social Psychology, 30, 813-835.

Depaola, S.J., Griffin, M., \& Young, J.R. (2003). Death anxiety and attitudes toward the elderly among adults: The role of gender and ethnicity. Death Studies, 27, 335-354.

Dijksterhuis, A., \& van Knippenberg, A. (1998). The relation between perception and behavior, or how to win a game of Trivial Pursuit. Journal of Personality and Social Psychology, $74,865-877$.

Dovidio, J.F., Kawakami, K., Johnson, C., Johnson, B., \& Howard, A. (1997). On the nature of prejudice: Automatic and controlled processes. Journal of Experimental Social Psychology, 33, 510-540.

Esposito, J.L. (1987). The obsolete self: Philosophical dimensions of aging. Los Angeles: University of California Press. 
Goldenberg, J.L., McCoy, S.K., Pyszczynski, T., Greenberg, J., \& Solomon, S. (2000). The body as a source of self-esteem: The effect of mortality salience on identification with one's body, interest in sex, and appearance monitoring. Journal of Personality and Social Psychology, 79, 118-130.

Greenberg, J., Pyszczynski, T., \& Solomon, S. (1986). The causes and consequences of a need for self-esteem: A terror management theory. In R.F. Baumeister (Ed.), Public and private self (pp.189-212). New York: Springer-Verlag.

Greenberg, J., Pysczcynski, T., Solomon, S., Rosenblatt, A., Veeder, M., Kirkland, S., \& Lyon, D. (1990). Evidence for terror management theory II: The effects of mortality salience on reactions to those who threaten or bolster the cultural worldview. Journal of Personality and Social Psychology, 58, 308-318.

Greenberg, J., Pysczcynski, T., Solomon, S., Simon, L., \& Breus, M. (1994). Role of consciousness and accessibility of death-related thoughts in mortality salience effects. Journal of Personality and Social Psychology, 67, 627-637.

Harmon-Jones, E., Greenberg, J., Solomon, S. (1996). The effects of mortality salience on intergroup bias between minimal groups. European Journal of Social Psychology, 26, $677-681$.

Hunter, K.I., Linn, M.W., \& Pratt, T.C. (1979). Minority women's attitudes about aging. Experimental Aging Research, 5, 95-108.

Jung, C.G. (1959). Aion researches in the phenomenology of the self. (R.F.C. Hull, Trans.). In H. Read, M. Fordham, \& G. Adler (Eds.), The collected works of C. G. Jung (Vol. 9, Part 2). Princeton, NJ: Princeton University Press. (Original work published in 1951).

Kite, M.E., \& Johnson, B.T. (1988). Attitudes toward older and younger adults: A meta -analysis. Psychology and Aging, 6, 19-27.

Kite, M.E., \& Wagner, L.S. (2002). Attitudes toward older adults. In T.D. Nelson (Ed.), Ageism: Stereotyping and prejudice against older people (pp. 129-200). Cambridge, MA: MIT Press.

Krueger, J., \& Clement, R.W. (1994). The truly false consensus effect: An ineradicable and egocentric bias in social perception. Journal of Personality and Social Psychology, 67, 596-610.

Lang, F.R., \& Carstensen, L.L. (2002). Time counts: Future time perspective, goals, and social relationships. Psychology and Aging, 17, 125-139.

Langer, S.K. (1982). Mind: An essay on human feeling. Volume III. Baltimore: The Johns Hopkins University Press.

Maglio, C.J., \& Robinson, S.E. (1994). The effects of death education on death anxiety: A meta-analysis. Omega: Journal of Death \& Dying, 29, 319-335.

McConnell, A.R., \& Leibold, J.M. (2001). Relations among the Implicit Association Test, discriminatory behavior, and explicit measures of racial attitudes. Journal of Experimental Social Psychology, 37, 435-442.

McGregor, H.A., Lieberman, J.D., Greenberg, J., Solomon, S., Arndt, J., Simon, L., \& Pysczcynski, T. (1998). Terror management and aggression: Evidence that mortality salience motivates aggression against worldview-threatening others. Journal of Personality and Social Psychology, 74, 590-605.

McGregor, I., Zanna, M.P., Holmes, J.G., \& Spencer, S.J. (2001). Compensatory 
conviction in the face of personal uncertainty: Going to extremes and being oneself. Journal of Personality and Social Psychology, 80, 472-488.

Montepare, J.M., \& Zebrowitz, L.A. (2002). A social-developmental view of ageism. In T.D. Nelson (Ed.), Ageism: Stereotyping and prejudice against older people (pp. 77125). Cambridge, MA: MIT Press.

Nelson, L.J., Moore, D.L., Olivetti, J., \& Scott, T. (1997). General and personal mortality salience and nationalistic bias. Personality and Social Psychology Bulletin, 23, 884-892.

Nelson, T.D. (2002). Preface. In T.D. Nelson (Ed.), Ageism: Stereotyping and prejudice against older people (ix-xiv). Cambridge, MA: MIT Press.

Oatley, K. \& Bolton, W. (1985). A social-cognitive theory of depression in reaction to life events. Psychological Review, 92, 372-388.

Palmore, E. (1999). Ageism: Negative and positive. (1999). New York: Springer Publishing Company, Inc.

Pasupathi, M., \& Lockenhoff, C.E. (2002). Ageist behavior. In T.D. Nelson (Ed.), Ageism: Stereotyping and prejudice against older people (pp. 201-246). Cambridge, MA: MIT Press.

Perdue, C.W., \& Gurtman, M.B. (1990). Evidence for the automaticity of ageism. Journal of Experimental Social Psychology, 26, 199-216.

Pyszczynski, T., Greenberg, J., \& Solomon, S., Sideris, J., \& Stubing, M.J. (1993). Emotional expression and the reduction of motivated cognitive bias: Evidence from cognitive dissonance from victims' paradigms. Journal of Personality and Social Psychology, 64, 177-186.

Pyszczynski, T., Greenberg, J., Solomon, S., Cather, C., Gat, I., \& Sideris, J. (1995). Defensive distancing from victims of serious illness: The role of delay. Personality and Social Psychology Bulletin, 21, 13-20.

Rodin, J., \& Langer, E. (1980). Aging labels: The decline of control and the fall of self-esteem. Journal of Social Issues, 36, 12-29.

Rosenblatt, A., Greenberg, J., Solomon, S., Pyszczynski, T., \& Lyon, D. (1989). Evidence for terror management theory I: The effects of mortality salience on reactions to those who violate or uphold cultural values. Journal of Personality and Social Psychology, 57, 681-690.

Schimel, J., Pyszczynski, T., Greenberg, J., O’Mahen, H., \& Arndt, J. (2000). Running from the Shadow: Psychological distancing from others to deny characteristics people fear in themselves. Journal of Personality and Social Psychology, 78, 446-462.

Schwiebert, D.C. (1978). Unfavorable stereotyping of the aged as a function of death anxiety, sex, perception of elderly relatives, and a death anxiety-repression interaction. Dissertation Abstracts International, 39 (6-B), 3007.

Shanks, A.Z. (1976). Old is what you get: Dialogues on aging by the old and young. New York: Viking Press.

Simon, L., Greenberg, J., Arndt, J., Psyzczynski, T., Clement, R., \& Solomon, J. (1997). Perceived consensus, uniqueness, and terror management: Compensatory responses to threats to inclusion and distinctiveness. Personality and Social Psychology Bulletin, 23, 1055-1065.

Taylor, S.E., \& Brown, J.D. (1994). Positive illusions and well-being revisited: Separating fact from fiction. Psychological Bulletin, 116, 21-27. 
Taylor, S. E., \& Mettee, D. R. (1971). When similarity breeds contempt. Journal of Personality and Social Psychology, 20, 75-81.

van den Bos, K. (2001). Uncertainty management: The influence of uncertainty salience on reactions to perceived procedural fairness. Journal of Personality and Social Psychology, 80, 931-941.

van den Bos, K., \& Miedema, J. (2000). Toward understanding why fairness matters: The influence of mortality salience on reactions to procedural fairness. Journal of Personality and Social Psychology, 79, 355-356.

Watson, D., \& Clark, L.A. (1991). Self- versus peer ratings of specific emotional traits: Evidence of convergent and discriminant validity. Journal of Personality and Social Psychology, 60, 927-940. 


\section{Notes}

1. Study 1 appeared at the end of another study. Only the details of the procedure relevant to the present study are described in the manuscript. However, the independent variables from the study that the current research followed were entered into an ANOVA to assess whether they affected scores on the death accessibility measure. No effects were significant, all $p \mathrm{~s}>.2$.

2. In Study 1 there was no main effect for gender, nor did the elderly prime manipulation interact with gender, all $p \mathrm{~s}>.2$. Gender, therefore, was not included in the final analysis. We also analyzed participants' ratings of the young versus old pictures in those participants who received both. In order to do this we averaged the ratings for the two old targets and averaged the ratings for each set of young targets. We then compared the ratings for the old targets to the ratings for whichever set of young targets the participants viewed in 5 separate ANOVAs with target (young vs. elderly) treated as a within subjects variable. The results revealed that the young targets were rated as more attractive $(M=$ $3.68)$ than the old targets $(M=2.97), F(1,45)=12.2, p<.01$; the young targets were rated as taller $(M=5,8.48$ ") than the elderly targets $(M=5,7.20 "), F(1,45)=9.61, p<$ .01 ; the young targets were rated as more powerful $(M=5.51)$ than the elderly targets $(M$ $=4.01), F(1,45)=32.57, p>.01$; the young targets were rated as more anxious $(M=$ 4.71) than the elderly targets $(M=4.17), F(1,45)=3.92, p=.05$; the young targets were not rated as more courageous or cowardly than the elderly targets, $F(1,45)=.60, p>.1$. Lastly, we took these ratings, for both older and younger people, and correlated them with death accessibility. No correlations were significant, all $p \mathrm{~s}>.35$.

3. One more effect, a gender by target interaction, was nearly significant, $F(1,88)=3.59, p$ $=.06$. Though both men and women were more distanced from the elderly than from teens (as the main effect attests to), this distance appeared more pronounced for men. Men were more distanced than women from the elderly, $t(94)=3.86, p<.05$, but were not significantly more distanced than women from teens, $t(94)=1.31, p>.15$.

4. Correlations were also computed between self and social desirability ratings to measure how favorably participants viewed themselves. A 2 (MS) X 2 (gender) X 2 (order) ANOVA yielded no effects, all $p \mathrm{~s}>.2$. The self-favorability means in the control and MS conditions were .60 and .65 , respectively, $p>.4$. In two additional analyses, we also regressed our elderly distancing dependent measure and elderly favorability dependent measure onto these self-favorability ratings along with MS. The self-favorability measure, perhaps reflecting self-esteem, did not interact with MS in either analysis, $p \mathrm{~s}>$ .3. Thus, self-favorability did not moderate the MS effects on distancing or derogation of elderly people.

5. Though the independent variables did not affect any of the eleven PANAS-X subscales, we nevertheless entered each of these subscales as covariates into independent MS X gender X target group X order ANCOVAs, to assess effects on the distancing and favorability findings. Though including some of the affect subscales as covariates raised the distancing and favorability MS by target group interactions just above .05 , all $p$ s were $<=.07$. Further, we tested the differences between the $p$-values from the original analyses against the ones obtained when including the affect subscales, and no changes in $p$-values approached significance, all $z \mathrm{~s}<.17, p \mathrm{~s}>.85$.

6. This questionnaire asked participants to write about the importance of one of three different topics potentially relevant to ageism: close relationships, wisdom, and physical 
activity. However, a manipulation check at the bottom of the form showed that people's notions about what was important were not effected in the intended manner, and thus the variable could not clearly or meaningfully contribute to our analysis. With this variable included in the distancing and favorability repeated measures ANOVAs, however, all the reported $p$-values remain of at least equal statistical significance.

7. Order of target presentation was not entered into the final analyses in Study 3. It produced no effects in Study 2, and similarly, did not show a main effect or interact with any other variables when entered into the equations in Study 3.

8. Similar to Study 2, we entered each of the PANAS-X subscales, along with MS and prior similarity, into independent regression analyses on distancing and favorability. The results were very similar to those originally obtained when not including these affect subscales. Though the key MS by prior similarity interactions did in some cases become marginal (all $p \mathrm{~s}<.095$ ), none of the $p$-values dropped significantly from their original values, all $z \mathrm{~s}<.25$, all $p \mathrm{~s}>.8$. 
Table 1

Effects of mortality salience on distancing from elderly and teenagers. Higher correlations reflect less distancing.

\begin{tabular}{|c|c|c|c|c|c|c|}
\hline & \multicolumn{5}{|c|}{$\underline{\text { Salience }}$} & \\
\hline & \multicolumn{2}{|c|}{ Dental Pain } & & \multicolumn{3}{|c|}{ Mortality } \\
\hline & $M$ & $S D$ & $N$ & $M$ & $S D$ & $N$ \\
\hline arget Group & & & & & & \\
\hline Teenagers & .40 & .34 & 48 & .43 & .28 & 4 \\
\hline Elderly & .11 & .28 & 48 & -.05 & .31 & 48 \\
\hline
\end{tabular}


Table 2

Effects of mortality salience on favorability towards elderly and teenagers. Higher correlations reflect greater favorability.

\begin{tabular}{|c|c|c|c|c|c|c|}
\hline & \multicolumn{5}{|c|}{ Salience } & \\
\hline & \multicolumn{2}{|c|}{ Dental Pain } & \multirow[b]{2}{*}{$N$} & \multicolumn{3}{|c|}{ Mortality } \\
\hline & $\bar{M}$ & $S D$ & & $\bar{M}$ & $\overrightarrow{S D}$ & $N$ \\
\hline arget Group & & & & & & \\
\hline Teen & .38 & .33 & 48 & .41 & .26 & 48 \\
\hline Elderly & .12 & 29 & 48 & -.04 & .32 & 48 \\
\hline
\end{tabular}


Figure 1. Distancing from elderly people as a function of MS and prior similarity. High and Low Similar participants are plotted at 1 standard deviation above and below the mean of prior reported similarity to the average elderly person.

NOTE: Distancing means reflect correlations between participants' self and elderly ratings during the experiment. Lower numbers reflect greater distancing.

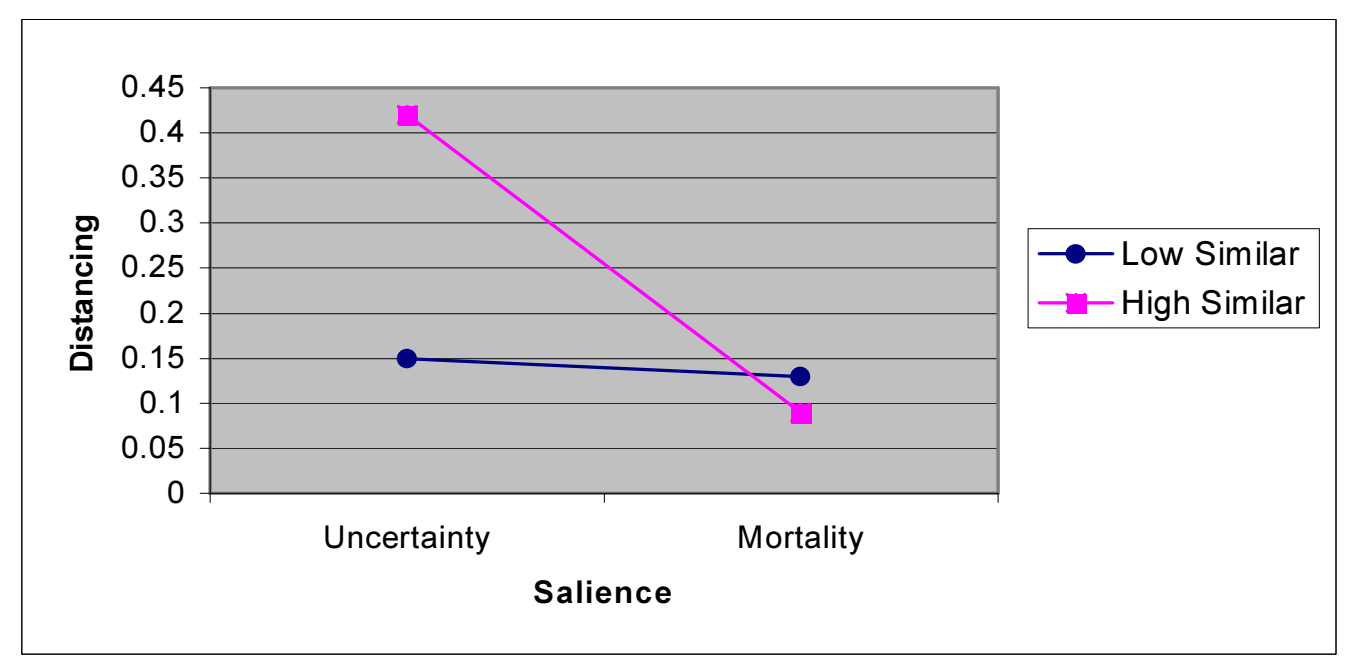


Figure 2. Favorability towards elderly people as a function of MS and prior similarity. High and Low Similar participants are plotted at 1 standard deviation above and below the mean of prior reported similarity to the average elderly person.

NOTE: Favorability means reflect correlations between participants' elderly and desirability ratings during the experiment. Higher numbers reflect greater favorability.

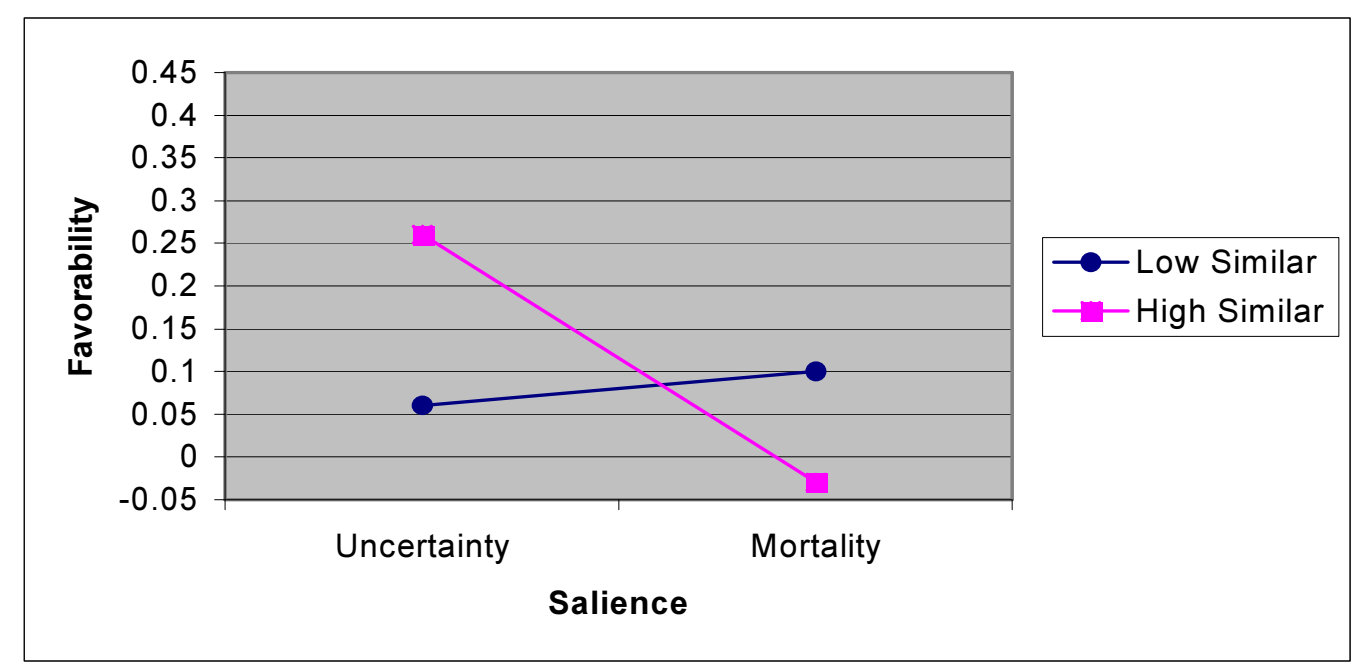

